\title{
Human mesenchymal stem cells are resistant to cytotoxic and genotoxic effects of cisplatin in vitro
}

\author{
Bruno Corrêa Bellagamba ${ }^{1,2}$, Bianca Regina Ribas de $\mathrm{Abreu}^{2}$, Ivana Grivicich ${ }^{2}$, Carolina Franke Markarian ${ }^{3}$, \\ Eduardo Chem ${ }^{3}$, Melissa Camassola ${ }^{2}$, Nance Beyer Nardi ${ }^{1,2}$ and Rafael Rodrigues Dihl ${ }^{2}$ \\ ${ }^{1}$ Programa de Pós-Graduação em Genética e Biologia Molecular, Universidade Federal do Rio Grande do \\ Sul, Porto Alegre, RS, Brazil. \\ ${ }^{2}$ Programa de Pós-Graduação em Biologia Celular e Molecular Aplicada à Saúde, Universidade Luterana \\ do Brasil, Canoas, RS, Brazil. \\ ${ }^{3}$ Complexo Hospitalar Santa Casa de Porto Alegre, Porto Alegre, RS, Brazil.
}

\begin{abstract}
Mesenchymal stem cells (MSCs) are known for their important properties involving multilineage differentiation potential, trophic factor secretion and localization along various organs and tissues. On the dark side, MSCs play a distinguished role in tumor microenvironments by differentiating into tumor-associated fibroblasts or supporting tumor growth via distinct mechanisms. Cisplatin (CIS) is a drug widely applied in the treatment of a large number of cancers and is known for its cytotoxic and genotoxic effects, both in vitro and in vivo. Here we assessed the effects of CIS on MSCs and the ovarian cancer cell line OVCAR-3, by MTT and comet assays. Our results demonstrated the resistance of MSCs to cell death and DNA damage induction by CIS, which was not observed when OVCAR-3 cells were exposed to this drug.
\end{abstract}

Keywords: Mesenchymal stem cells, Cisplatin, MTT, Comet assay, OVCAR-3 cells.

Received: February 28, 2015; Accepted: August 11, 2015.

Cisplatin, Cis-diamminedichloroplatinum-II, (CIS) is a widely used chemotherapeutic agent as the first line treatment against head and neck, testicular, lung, ovarian and others types of cancer (Jamieson and Lippard, 1999; Gomez-Ruiz et al., 2012). Its main mechanism of action involves formation of adducts covalently linked to DNA (Sancho-Martinez et al., 2012). These adducts are considered the major contributing factor to the cytotoxic effects of the drug, since they block DNA replication and transcription and, ultimately, cell division (Dasari and Tchounwou, 2014). Despite the well-established application of CIS in clinical treatments, intrinsic or acquired cell resistance to this drug is a serious problem that appears concomitant with CIS utilization (Galluzzi et al., 2012).

Mesenchymal stem cells (MSCs) are post-natal stem cells found in almost all tissues in the organism (da Silva Meirelles et al., 2006), including human adipose tissue (Zuk et al., 2002), since they inhabit a perivascular niche (da Silva Meirelles et al., 2008). MSCs can secrete trophic factors such as anti-apoptotic, immunomodulatory, angio-

Send correspondence to Rafael Rodrigues Dihl, Laboratório da Toxicidade Genética, PPGBioSaúde, ULBRA, Prédio 22, 4ํandar, sala 20, Avenida Farroupilha, 8001, 92425-900, Canoas, RS, Brazil. E-mail: rafael.rodrigues@ulbra.br genic and chemo attractive molecules, which act in lesion and surrounding sites in vivo to promote tissue repair (Doorn et al., 2012). Another property of MSCs is the potential to differentiate into bone, cartilage and adipocytes (Zhu et al., 2012) according to the culture conditions. Due to their capacity to differentiate into various cell types and their paracrine effects, MSCs have emerged as a promising alternative for cell therapy and tissue engineering (Schaffler and Buchler, 2007).

While MSCs exert important roles in the maintenance of organismic homeostasis, they are also known for composing the tumor stroma and for their tropism to various types of cancer (Kucerova and Skolekova, 2013). In vitro analyses suggest that MSCs can stimulate tumor progression by modulating cytokine secretion, supressing the immune system, migrating to the tumor site and promoting tumor growth through paracrine factors, or by differentiating into tumor-associated fibroblasts. When MSCs are injected at the tumor site in vivo, they stimulate tumor growth and support metastasis, or inhibit tumorigenesis by antitumor effects involving downregulation of Akt, betacatenin, Bcl-2, c-Myc, proliferating cell nuclear antigen and surviving, leading to reduced proliferation, G1 arrest, suppression of oncogenes and increased apoptosis (Klopp et al., 2011). 
Given the complexity of the tumor microenvironment and the increasing evidence for the contribution of tumor-associated fibroblasts to cancer maintenance and chemoresistance (Houthuijzen et al., 2012), tumorassociated fibroblasts have been considered as promising targets for novel chemotherapeutic strategies (Samples et al., 2013). Several studies have shown the cytotoxic (Smith et al., 2005) and genotoxic (Unger et al., 2009) effects of CIS on ovarian carcinoma cells (OCCs) and normal proliferating and non-proliferating cells (Sancho-Martinez et al., 2012). However, the genotoxic effects of CIS on MSCs are still not clear, even though these cells are known for being resistant to several chemotherapeutic agents in vitro, including CIS (Li et al., 2004; Liang et al., 2011). Thus, due to the well known importance of MSCs for generating tumor-associated fibroblasts and their role in the cancer microenvironment and chemoresistance, the present study aimed at evaluating the cytotoxic effect and DNA damage induction potential of CIS on human adipose-derived MSCs and OCCs line OVCAR-3 during in vitro cultivation.

Human adipose-derived MSCs were obtained from adipose tissue of four patients undergoing elective liposuction surgery. All patients signed an informed consent form, and the study was approved by the Research Ethics Committee of Complexo Hospitalar Santa Casa de Misericórdia de Porto Alegre. The stromal vascular fraction was isolated as described by Zuk et al. (2002). Briefly, the liposuction material was extensively washed with phosphate buffered saline (PBS) and incubated with type I collagenase. Mononuclear cells resulting from tissue digestion and centrifugation were resuspended in Dulbecco's modified Eagle medium (DMEM) supplemented with HEPES (free acid, $3.7 \mathrm{~g} / \mathrm{L}$ ), 10\% fetal bovine serum (FBS, Cultilab, São Paul$\mathrm{o}$, Brazil) and 1\% penicillin/streptomycin (Cell Culture Medium 1 - CCM1). Cells were seeded at $3 \times 10^{4}$ cells $/ \mathrm{cm}^{2}$ into tissue culture flasks and expanded at $37^{\circ} \mathrm{C}$ in a humidified culture chamber with a $5 \% \mathrm{CO}_{2}$ atmosphere, changing the culture medium every $2-3$ days. Cells between passages 6 and 9 were used in all experiments. Immunophenotyping of MSCs was done using a BD FACSCalibur flow cytometer to determinate the presence/absence of the following cell markers: CD13, CD69, CD73, CD90, CD117 and HLA-DR (Figure 1). All reagents used here were from Sigma Chemical Co. (St Louis, MO, USA), unless otherwise stated. Plasticware was from TPP (Trasadingen, Switzerland).

The ovarian cancer cell line OVCAR-3 was purchased from ATCC (American Type Culture Collection, Manassas, Virginia, USA) and cultured with DMEM supplemented with $10 \%$ of FBS and $1 \%$ penicillin/streptomycin (Cell Culture Medium $2-\mathrm{CCM} 2$ ) at $37{ }^{\circ} \mathrm{C}$ in a humidified culture chamber with $5 \% \mathrm{CO}_{2}$. Cells were expanded according to the experiments requirement.

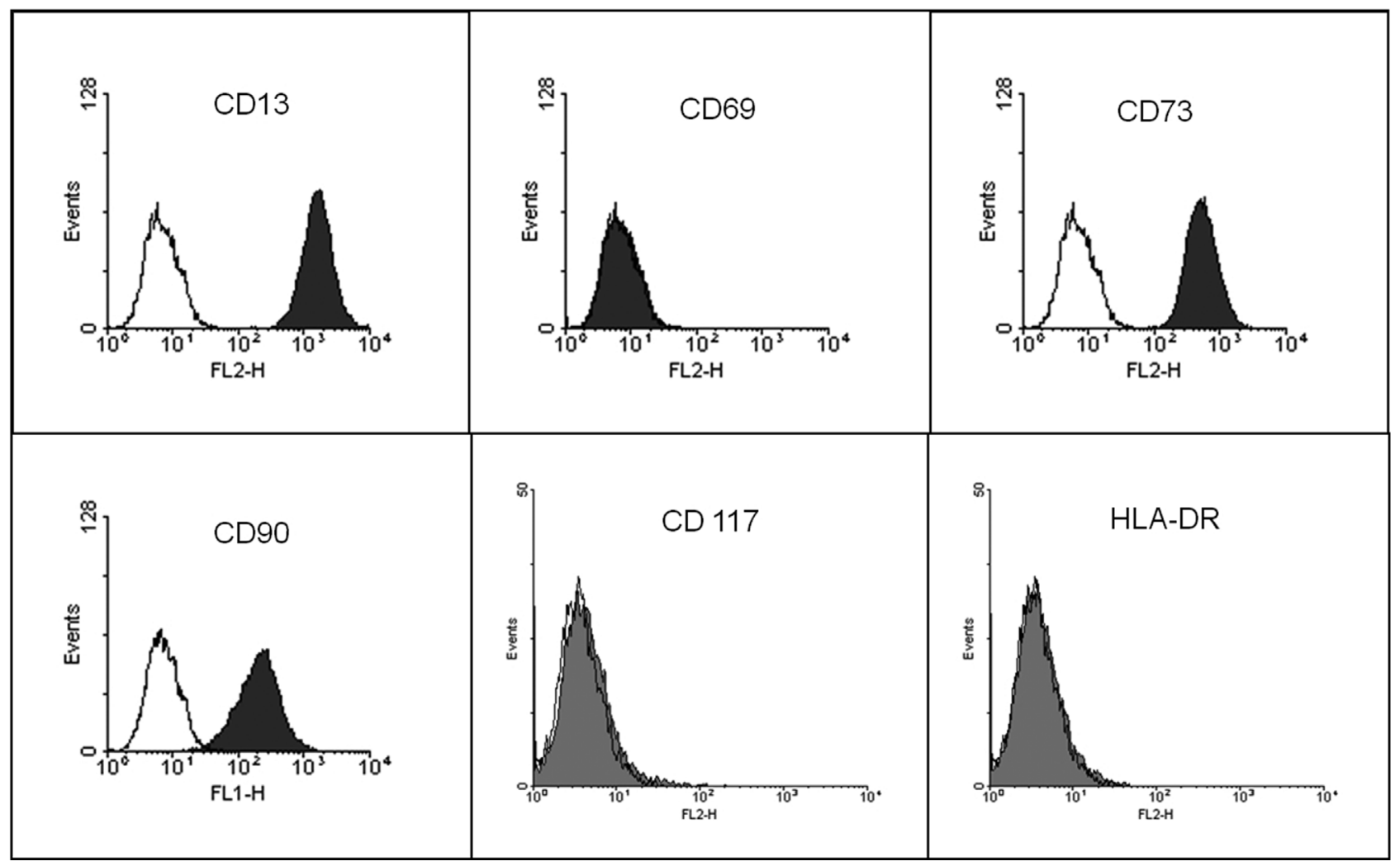

Figure 1 - Immunophenotypic profile of cultured human adipose-derived MSCs. Cells expressed CD13, CD73 and CD90, but did not express CD69, CD117 and HLA-DR markers. 
Cisplatin (CIS, CAS No.15663-27-1) was obtained as the clinical preparation Platistine ${ }^{\circledR}$ (Pfizer Ltda., São Paulo, Brazil). Ethyl methanesulfonate (EMS, CAS No.62-50-0) was purchased from Sigma-Aldrich. Solutions of CIS and EMS were made with CCMs immediately before use.

For the MTT assay evaluation of CIS cytotoxicity, cells were seeded in 96-well plates at a density of $3 \times 10^{3}$ cells/well for MSCs and $5 \times 10^{4}$ cells/well for OVCAR-3 cells and treated the following day with CIS at 0.5, 1, 3, 5, 10 and $50 \mu \mathrm{M}$ dosages. CCMs, 1 and 2, were used as negative control (NC). After 72 hours, CCMs were removed and $20 \mu \mathrm{L}$ of 3-(4,5-dimethylthiazol-2-yl)-2,5-diphenyl tetrazolium bromide (MTT) solution $(5 \mathrm{mg} / \mathrm{mL})$ was added to each well and incubated at $37^{\circ} \mathrm{C}$ for $2 \mathrm{~h}$. Formazan crystals resulting from the cleavage of MTT were dissolved in $100 \mu \mathrm{L}$ DMSO for 5 min with shaking. Each plate was read immediately in a microplate reader (Thermo Scientific, Waltham, MA) at a wavelength of $540 \mathrm{~nm}$. Three independent experiments were performed in triplicate for each type of cell culture. Cell viability is expressed in Figure 2 as percentage of the viability of untreated cells. Since the percentage of viable cells was calculated considering the average absorbance from cells of NCs, standard deviations of these groups of treatment are variable. The determination of the $50 \%$ inhibition concentration $\left(\mathrm{IC}_{50}\right)$ of CIS for each cell type was carried out by the sigmoidal fitting method (Sebaugh, 2011).

To detect DNA strand breaks and alkali labile as well as incomplete excision repair sites, we used the alkaline single-cell microgel electrophoresis (Comet) assay as described previously (Tice et al., 2000). MSCs and OVCAR3 cells were treated for 1 and $24 \mathrm{~h}$ with three concentrations of CIS, 3, 5 and $10 \mu \mathrm{M}$. These drug dosages were chosen considering viability of at least $70 \%$ of cells treated for $24 \mathrm{~h}$ with CIS (data not shown). We used ethyl methanesulfonate (EMS) $5 \mathrm{mM}$ as positive control (PC). After treatments, viable cells were trypsinized, resuspended in

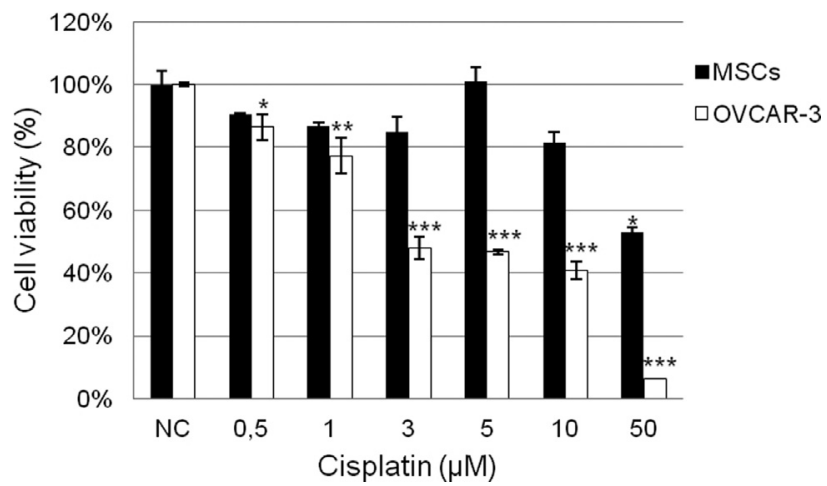

Figure 2 - Percentage of viable cells, evaluated by MTT assay, after $72 \mathrm{~h}$ of exposure to increasing concentrations of cisplatin (CIS). Black bars represent MSCs and white bars correspond to OVCAR-3 cells. NC: Negative Control. $* \mathrm{P}<0.05 ; * * \mathrm{P}<0.01 ; * * * \mathrm{P}<0.001$
0.5\% low melting agarose (Invitrogen Co, Carlsbad, CA) and distributed onto slides (Knittel Glaser, Braunschweig, Germany) previously coated with $1.5 \%$ normal melting agarose (Invitrogen Co, Carlsbad, CA). After cell lysis for $24 \mathrm{~h}$ in alkaline lysis buffer (10\% DMSO, 1\% Triton-X, 2.5 $\mathrm{M} \mathrm{NaCl}, 10$ mM Tris, 100 mM EDTA, pH 10), slides were placed in a horizontal gel electrophoresis chamber and covered with alkaline buffer $(5 \mathrm{mM} \mathrm{NaOH}$ and $200 \mathrm{mM}$ EDTA) at $\mathrm{pH}>13$. After a $20 \mathrm{~min}$ period for DNA denaturation, electrophoresis was performed under standard conditions $(1 \mathrm{~V} / \mathrm{cm}, 300 \mathrm{~mA}$, distance between electrodes $36 \mathrm{~cm})$ for $20 \mathrm{~min}$. Following neutralization at $\mathrm{pH} 7.5$ (0.4 M Tris), cells were stored until analysis. All preparation steps were performed under red or yellow light to avoid DNA damage by UV light.

The slides were analyzed in an Olympus System Microscope (Model BX41) equipped with a Olympus Reflected Fluorescence System (Model U-RFL-T) and Olympus U-TV0.35XC-2 Camera (Tokyo, Japan). After coding and blinding of the slides, they were stained with ethidium bromide solution and the comets were determined by an image analysis system (Comet Assay IV, Perceptive Instruments, UK). Four slides with 25 cells (total of 100 cells) for every test sample were counted and analyzed for the Tail Length (TL) parameter to quantify the induced DNA damage. Data from TL are given in Table 1. Results are given as mean \pm standard deviation (SD).

Statistical analysis of the obtained data was performed using the SPSS software, version 13.0. To analyze differences, One Way ANOVA with Dunnett post hoc test was applied, where the drug treatments were compared against the negative control. Differences were considered statistically significant when the P-value was less than 0.05 .

After $72 \mathrm{~h}$ of treatment, MSCs, but not OVCAR-3 cells, showed resistance to the increasing concentrations of CIS when evaluated by MTT assay (Figure 2, black bars). We assumed a reduction above $50 \%$ of cell viability for treated cells in relation to $\mathrm{NC}$ as indication of cytotoxicity. The cell percentage for OVCAR-3 cells was highly reduced, in comparison with the NC, showing their sensitivity to the drug (Figure 2, white bars). In addition, due to the high cytotoxic effect of CIS on OVCAR-3 cells, we calculated the $\mathrm{IC}_{50}$ value, that was found to be $2.86 \mu \mathrm{M}$.

We assessed genotoxic potential of CIS by Comet assay during two times of exposure ( 1 and $24 \mathrm{~h}$ ) by tail length (TL) analysis, as migration distance of DNA in $\mu \mathrm{m}$. After the two times of exposure to the drug, no DNA damage was observed in MSCs for all tested dosages, with exception of PC (Table 1). However, CIS was able to induce DNA damage in OVCAR-3 cells during the two times of exposure (Table 1). After $1 \mathrm{~h}$ of treatment, all dosages of CIS caused a significant increase in DNA migration (TL) in OVCAR-3 cells in comparison to NC. TL was also significantly higher 
Table 1 - Results of the Comet assay on MSCs and OVCAR-3 cells after treatment with CIS

\begin{tabular}{|c|c|c|c|}
\hline & MSCs & $1 \mathrm{~h}$ treatment & $24 \mathrm{~h}$ treatment \\
\hline & Drug Concentrations & Mean \pm Standard Deviation & Mean \pm Standard Deviation \\
\hline \multirow[t]{7}{*}{$\mathrm{TL}$} & $\mathrm{NC}$ & $35.43 \pm 5.94$ & $35.51 \pm 8.66$ \\
\hline & CIS $3 \mu \mathrm{M}$ & $35.32 \pm 8.49$ & $23.59 \pm 9.88$ \\
\hline & CIS $5 \mu \mathrm{M}$ & $40.05 \pm 15.58$ & $23.05 \pm 7.90$ \\
\hline & CIS $10 \mu \mathrm{M}$ & $39.11 \pm 7.86$ & $22.17 \pm 7.93$ \\
\hline & $\mathrm{PC}$ & $75.92 \pm 48.39^{* *}$ & $158.45 \pm 22.13 * * *$ \\
\hline & OVCAR-3 & $1 \mathrm{~h}$ treatment & $24 \mathrm{~h}$ treatment \\
\hline & Drug Concentrations & Mean \pm Standard Deviation & Mean \pm Standard Deviation \\
\hline \multirow[t]{5}{*}{ TL } & $\mathrm{NC}$ & $33.21 \pm 7.47$ & $33.15 \pm 8.04$ \\
\hline & CIS $3 \mu \mathrm{M}$ & $66.62 \pm 23.22 * *$ & $56.05 \pm 23.36^{*}$ \\
\hline & CIS $5 \mu \mathrm{M}$ & $68.39 \pm 24.85^{* *}$ & $72.17 \pm 28.36^{* *}$ \\
\hline & CIS $10 \mu \mathrm{M}$ & $57.39 \pm 17.13^{*}$ & $71.18 \pm 21.32 * *$ \\
\hline & $\mathrm{PC}$ & $103.86 \pm 29.92 * * *$ & $147.30 \pm 77.33 * * *$ \\
\hline
\end{tabular}

in OVCAR-3 cells treated with CIS after $24 \mathrm{~h}$ of exposure, at 3,5 and $10 \mu \mathrm{M}$ dosages, in relation to $\mathrm{NC}$.

In this study we demonstrated the resistance of human adipose-derived MSCs to the exposure of increasing concentrations of CIS during $72 \mathrm{~h}$ of in vitro cultivation (Figure 2, black bars). Our data are in agreement with results obtained by Liang et al. (2011), which showed the resistance and recovery of human adipose-derived MSCs to CIS exposure. They also demonstrated that MSCs retain their phenotypical characteristics, such as a fibroblast-like morphology and stem cell marker expression, as well as their multilineage differentiation capacity.

In contrast, CIS was able to dramatically reduce the viability of OVCAR-3 cells after $72 \mathrm{~h}$ of treatment (Figure 2 , white bars). The $\mathrm{IC}_{50}$ value of CIS for OVCAR-3 cells was $2.86 \mu \mathrm{M}$, which means that CIS was, at least, 17 fold more cytotoxic for OVCAR-3 cells than for MSCs, since the highest tested dosage of CIS $(50 \mu \mathrm{M})$ was not able to reduce MSC viability above $50 \%$. The sensitivity of OVCAR-3 cells to CIS is in accordance with previously data demonstrated by several studies (Smith et al., 2005; Karaca et al., 2013).

After confirming the resistance of MSCs to CIS we chose three dosages $(3,5$ and $10 \mu \mathrm{M})$ to evaluate the genotoxic potential of this drug on MSCs and OVCAR-3 cells. Using the Comet assay, we were able to demonstrate, for the first time, the absence of DNA damage caused by CIS on MSCs (Table 1) after 1 and $24 \mathrm{~h}$ of treatment, in our experimental conditions. In contrast, CIS significantly increased DNA migration of OVCAR-3 cells comets (Table 1), showing its genotoxic effect. In addition, our results demonstrate that the concentrations of CIS used in this study were not associated with retarded DNA migration, as expected by interstrand DNA cross-links, observed for treatments with concentrations above $50 \mu \mathrm{M}$ of CIS (Almeida et al., 2006; Pang et al., 2007).

CIS is a strong genotoxic and mutagenic agent (Roos and Kaina, 2013). It is able to induce DNA damage in a broad range of eukaryotic cells, from Drosophila melanogaster to humans, either in vitro and in vivo. Because of its capacity to cause DNA adducts, CIS induced DNA strand breaks in D. melanogaster somatic cells in vivo, evaluated by the Comet assay (Garcia Sar et al., 2012) and SMART test (Danesi et al., 2010). A large panel of mammalian cells have already been exposed to CIS, and its genotoxic potential has been confirmed on cells from hamster (Brozovic et al., 2009), mice (Narayana, 2012), rats (Mendonça et al., 2010) and human normal and cancer cells (Blasiak et al., 2000; Shimabukuro et al., 2011). Although CIS is a widely used drug for the treatment of a broad range of cancers, tumor resistance to CIS is an issue to be surpassed. The main mechanisms of cell resistance to CIS are described as: decreasing intracellular accumulation of CIS, increasing intracellular trapping of CIS, increased repair of DNA damage or increased tolerance of DNA damage and, finally, the mixture of a variety of others and before mentioned mechanisms (Borst et al., 2008).

Here we demonstrated that human MSCs are strongly resistant to CIS exposure, considering this drug as a cytotoxic and genotoxic agent, but the mechanisms underlying this property are still poorly understood. It was shown that human bone marrow MSCs can be isolated from patients after high-dose or standard chemotherapy and the cells retained their MSCs characteristics (Mueller et al., 2006). These authors also demonstrated that MSCs have an elevated threshold for CIS-induced apoptosis, which was characterized by a lack of caspase- 9 activity in apoptotic 
cells and an increased p53 expression, independent of apoptosis induction (Mueller et al., 2006). p73 also seems to play a role in MSC resistance to CIS, since the overexpression induction of this apoptosis regulator sensibilizes human bone marrow MSCs to CIS treatment (Liang et al., 2010). Prendergast et al. (2011) showed that CIS can activate DNA damage response pathways, including induction of p53 and p21, and activation of PI3 kinase-related protein kinase (PIKK)-dependent phosphorylation of histone $\mathrm{H} 2 \mathrm{AX}$ on serine 139 , and replication protein $\mathrm{A} 2$ on serine4/serine8, in human bone marrow MSCs. Taken together, these findings indicate that the resistance of MSCs to CIS results from complex cellular pathways, involving alteration of apoptosis regulation and activation of molecules engaged in DNA repair process. Our data suggest that the tolerance of MSCs to DNA damage, potentially induced by CIS, could also be related to the resistance of these cells to the drug. Finally, we emphasize the need for further investigations aiming to elucidate the mechanisms responsible for MSC resistance to drugs, since the importance of these cells in the tumor microenvironment context is well known.

\section{Acknowledgments}

The authors thank CNPq, FAPERGS and ULBRA for financially support for this study.

\section{References}

Almeida GM, Duarte TL, Steward WP and Jones GD (2006) Detection of oxaliplatin-induced DNA crosslinks in vitro and in cancer patients using the alkaline comet assay. DNA Repair (Amst) 5:219-225.

Blasiak J, Kowalik J, Malecka-Panas E, Drzewoski J and Wojewodzka M (2000) DNA damage and repair in human lymphocytes exposed to three anticancer platinum drugs. Teratog Carcinog Mutagen 20:119-131.

Borst P, Rottenberg S and Jonkers J (2008) How do real tumors become resistant to cisplatin? Cell Cycle 7:1353-359.

Brozovic A, Damrot J, Tsaryk R, Helbig L, Nikolova T, Hartig C, Osmak M, Roos WP, Kaina B and Fritz G (2009) Cisplatin sensitivity is related to late DNA damage processing and checkpoint control rather than to the early DNA damage response. Mutat Res 670:32-41.

da Silva Meirelles L, Chagastelles PC and Nardi NB (2006) Mesenchymal stem cells reside in virtually all post-natal organs and tissues. J Cell Sci 119:2204-2213.

da Silva Meirelles L, Caplan AI and Nardi NB (2008) In search of the in vivo identity of mesenchymal stem cells. Stem Cells 26:2287-2299.

Danesi CC, Bellagamba BC, Dihl RR, de Andrade HH, Cunha KS, Spano MA, Reguly ML and Lehmann M (2010) Mutagenic evaluation of combined paclitaxel and cisplatin treatment in somatic cells of Drosophila melanogaster. Mutat Res 696:139-143.

Dasari S and Tchounwou PB (2014) Cisplatin in cancer therapy: molecular mechanisms of action. Eur $\mathrm{J}$ Pharmacol 740:364-378.
Doorn J, Moll G, Le Blanc K, van Blitterswijk C and de Boer J (2012) Therapeutic applications of mesenchymal stromal cells: paracrine effects and potential improvements. Tissue Eng Part B Rev 18:101-115.

Galluzzi L, Senovilla L, Vitale I, Michels J, Martins I, Kepp O, Castedo M and Kroemer G (2012) Molecular mechanisms of cisplatin resistance. Oncogene 31:1869-1883.

Garcia Sar D, Aguado L, Montes Bayon M, Comendador MA, Blanco Gonzalez E, Sanz-Medel A and Sierra LM (2012) Relationships between cisplatin-induced adducts and DNA strand-breaks, mutation and recombination in vivo in somatic cells of Drosophila melanogaster, under different conditions of nucleotide excision repair. Mutat Res 741:81-88.

Gomez-Ruiz S, Maksimovic-Ivanic D, Mijatovic S and Kaluderovic GN (2012) On the discovery, biological effects, and use of Cisplatin and metallocenes in anticancer chemotherapy. Bioinorg Chem Appl 2012:140284.

Houthuijzen JM, Daenen LG, Roodhart JM and Voest EE (2012) The role of mesenchymal stem cells in anti-cancer drug resistance and tumour progression. Br J Cancer 106:1901-196.

Jamieson ER and Lippard SJ (1999) Structure, recognition, and processing of Cisplatin-DNA adducts. Chem Rev 99:24672498.

Karaca B, Atmaca H, Bozkurt E, Kisim A, Uzunoglu S, Karabulut B, Sezgin C, Sanli UA and Uslu R (2013) Combination of AT-101/cisplatin overcomes chemoresistance by inducing apoptosis and modulating epigenetics in human ovarian cancer cells. Mol Biol Rep 40:3925-3933.

Klopp AH, Gupta A, Spaeth E, Andreeff M and Marini F (2011) Concise review: dissecting a discrepancy in the literature: do mesenchymal stem cells support or suppress tumor growth? Stem Cells 29:11-19.

Kucerova L and Skolekova S (2013) Tumor microenvironment and the role of mesenchymal stromal cells. Neoplasma 60:1-10.

Li J, Law HK, Lau YL and Chan GC (2004) Differential damage and recovery of human mesenchymal stem cells after exposure to chemotherapeutic agents. Br J Haematol 127:326334.

Liang W, Lu C, Li J, Yin JQ and Zhao RC (2010) p73alpha regulates the sensitivity of bone marrow mesenchymal stem cells to DNA damage agents. Toxicology 270:49-56.

Liang W, Xia H, Li J and Zhao RC (2011) Human adipose tissue derived mesenchymal stem cells are resistant to several chemotherapeutic agents. Cytotechnology 63:523-530.

Mendonça LM, dos Santos GC, dos Santos RA, Takahashi CS, Bianchi M de L and Antunes LM (2010) Evaluation of curcumin and cisplatin-induced DNA damage in PC12 cells by the alkaline comet assay. Hum Exp Toxicol 29:635-643.

Mueller LP, Luetzkendorf J, Mueller T, Reichelt K, Simon H and Schmoll HJ (2006) Presence of mesenchymal stem cells in human bone marrow after exposure to chemotherapy: evidence of resistance to apoptosis induction. Stem Cells 24:2753-2765.

Narayana K (2012) Effects of L-ascorbic acid on two cycles of cisplatin-induced DNA double-strand breaks and phosphorylation of p53 in the liver. Exp Toxicol Pathol 64:495-502.

Pang SK, Yu CW, Au-Yeung SC and Ho YP (2007) DNA damage induced by novel demethylcantharidin-integrated platinum 
anticancer complexes. Biochem Biophys Res Commun $363: 235-240$

Prendergast AM, Cruet-Hennequart S, Shaw G, Barry FP and Carty MP (2011) Activation of DNA damage response pathways in human mesenchymal stem cells exposed to cisplatin or gamma-irradiation. Cell Cycle 10:3768-3777.

Roos WP and Kaina B (2013) DNA damage-induced cell death: from specific DNA lesions to the DNA damage response and apoptosis. Cancer Lett 332:237-248.

Samples J, Willis M and Klauber-Demore N (2013) Targeting angiogenesis and the tumor microenvironment. Surg Oncol Clin N Am 22:629-639.

Sancho-Martinez SM, Prieto-Garcia L, Prieto M, Lopez-Novoa JM and Lopez-Hernandez FJ (2012) Subcellular targets of cisplatin cytotoxicity: an integrated view. Pharmacol Ther 136:35-55.

Schaffler A and Buchler C (2007) Concise review: adipose tissue-derived stromal cells - basic and clinical implications for novel cell-based therapies. Stem Cells 25:818-827.

Sebaugh JL (2011) Guidelines for accurate EC50/IC50 estimation. Pharm Stat 10:128-134.

Shimabukuro F, Neto CF, Sanches Jr JA and Gattas GJ (2011) DNA damage and repair in leukocytes of melanoma patients exposed in vitro to cisplatin. Melanoma Res 21:99-105.
Smith JA, Ngo H, Martin MC and Wolf JK (2005) An evaluation of cytotoxicity of the taxane and platinum agents combination treatment in a panel of human ovarian carcinoma cell lines. Gynecol Oncol 98:141-145.

Tice RR, Agurell E, Anderson D, Burlinson B, Hartmann A, Kobayashi H, Miyamae Y, Rojas E, Ryu JC and Sasaki YF (2000) Single cell gel/comet assay: guidelines for in vitro and in vivo genetic toxicology testing. Environ Mol Mutagen 35:206-221.

Unger FT, Klasen HA, Tchartchian G, de Wilde RL and Witte I (2009) DNA damage induced by cis- and carboplatin as indicator for in vitro sensitivity of ovarian carcinoma cells. BMC Cancer 9:1471-2407.

Zhu X, Shi W, Tai W and Liu F (2012) The comparison of biological characteristics and multilineage differentiation of bone marrow and adipose derived mesenchymal stem cells. Cell Tissue Res 350:277-287.

Zuk PA, Zhu M, Ashjian P, De Ugarte DA, Huang JI, Mizuno H, Alfonso ZC, Fraser JK, Benhaim P and Hedrick MH (2002) Human adipose tissue is a source of multipotent stem cells. Mol Biol Cell 13:4279-4295.

Associate Editor: Carlos R. Machado

License information: This is an open-access article distributed under the terms of the Creative Commons Attribution License (type CC-BY), which permits unrestricted use, distribution and reproduction in any medium, provided the original article is properly cited. 